\title{
Characterization of Impact Damage in Composite Plates
}

\author{
Bibi Intan Suraya Murat ${ }^{1}$ - Paul Fromme ${ }^{2}$ - Marco Endrizzei ${ }^{3}$ - Alessandro Olivo $^{3}$ \\ ${ }^{1}$ Faculty of Mechanical Engineering, University Technology MARA, Malaysia \\ 2 University College London, Department of Mechanical Engineering, UK \\ 3 University College London, Department of Medical Physics and Biomedical Engineering, UK
}

Low-velocity impact on composites typically produces a barely visible damage at the impacted surface. The internal defects can be complex, consisting of multimode damage and the extent of the impact damage normally spreads across the thickness under the impacted surface. The characterization of impact damage in composites can be very complicated and varies for every different composite structure. In this paper, independent characterization of the low-velocity impact damage on carbon-fiber/epoxy plates using three different non-destructive evaluation methods were used. The goal is to demonstrate the ability of guided ultrasonic waves imaging technique and compared to the more widely employed techniques such as X-ray imaging and ultrasonic immersion C-scan. It was demonstrated that the low frequency $A_{0}$ guided ultrasonic wave mode generated by a low-cost piezoelectric transducer can be successfully employed to detect impact damage in composite plates and managed to estimate the size and shape of the impact damage.

Keywords: low-velocity impact, composite plates, X-ray, ultrasonic C-scan, guided waves

Highlights

- Independent characterization of the impact damage using three different NDE methods: X-ray imaging, ultrasonic immersion C-scan and guided ultrasonic waves.

- $\quad X$-ray can indicate local fiber debonding and mark the area of matrix cracks.

- Ultrasonic C-scan provides a useful approximation of size and depth of the impact damage.

- The guided ultrasonic waves efficiently localize the impact location and provide details of the impact damage such as depth, exact length and width of the impact damage.

\section{O INTRODUCTION}

Composites are widely used in various applications such as aircraft because of their unique properties that can be tailored to meet specific requirements. Often composites are in the form of laminates, made of layers of different fiber orientations that are bonded together. One major concern related to composite structural integrity is the susceptibility of composite materials to incur low-velocity impact damage. The failure process caused by low-velocity impact in composites is a complex phenomenon. Matrix cracking, delamination, fiber debonding and fiber breakage are examples of various failure modes [1].

Interface delamination in cross-ply composites is of particular interest because it can lead to a significant loss of load carrying capacity. In contrast to matrix cracks or fiber breakage, delamination can occur in the absence of any visible damage, making it difficult to detect by a visual inspection as it normally does not appear on the surface [2]. Hence, it can be concluded that delaminations developed at the initial stage of an impact event are more dangerous to the structural integrity, as they could continue to expand and spread to the entire structure. Failure to detect this internal damage at an early stage may result in a catastrophic failure of the composite structure. This concern provided the motivation for this study.

Currently, the aerospace industry utilizes a variety of NDE methods for post-fabrication and inservice inspection. The commonly used NDE methods are as follows: visual inspection, eddy current, magnetic particle, radiography, thermography and ultrasonic inspection. Most of the methods are limited to the detection of flaws that lie near the surface such as surface cracks, corrosion and other structural defects. Radiography inspection is especially suited for the inspection of internal defects that cannot be detected by visual inspection. However, it requires parts to be detached or dismantled first, hence consuming significant inspection time. Acoustic emission technique [3], electrical resistance method [4] and embedded sensors in composites for online monitoring [5] are some of the advanced NDE methods that are able to provide damage information. However, some of these methods might be less suited for the inspection of an aircraft in noisy environments. Ultrasonic C-scans can produce very sensitive measurements of the location and size of damage, but requires removal of test-parts from the structure and the test part needs to be immersed in a water tank. This causes significance disruption to service operation. The condition of the monitored structure can be 
easily obtained using ultrasonic double throughtransmission, but it is rather impractical for inspecting large structures when access is limited. Ultrasonic inspection techniques where air-coupling is used are an alternative, but known to be less sensitive to defects [6]. High wave attenuation associated with the composite properties and high frequency transducers limits the inspection on large complex structures. Ultrasonic phased array [7] and tomography [8] have recently been utilized more in aircraft SHM as they can produce high resolution images. However the biggest problem with these methods is the requirement of good coupling and a constant angle of incidence for reproducible inspection results.

The shortcomings of current methods indicate a need for rapid inspection, online monitoring and cost-effective methods for the inspection of large composite structures. One possible method is the guided ultrasonic wave method. The ability to inspect a structure from a single transducer position results in a simple and fast inspection [9]. For the realization of reliable NDE techniques in composites, the aim of this study is to present the characteristic of impact damage in composite plates using three different NDE methods.

\section{METHODS}

Two specimens were supplied by the Composite Systems Innovation Centre, University of Sheffield, which had been investigated in a separate study [4]. The composite plates $(990 \mathrm{~mm} \times 110 \mathrm{~mm} \times 2 \mathrm{~mm})$ were fabricated with unidirectional prepregs by autoclave cure using Cytec 977-2 / Tenax HTS crossply laminates. The plates consist of 8 prepreg layers with a symmetric layup sequence of $[0 / 90]_{2 s}$. The specimens were subjected to a $7.4 \mathrm{~J}$ impact damage using a hemispherical $15 \mathrm{~mm}$ impactor head and following standard drop weight impact procedures. A small degree of fiber fracture and indentation is visible on the surface of the plates.

In order to reveal the extent of the impact damage, the NDE measurements were performed on the defective composite plates for the detection and characterization of impact damage. The following section describes the procedure as well as their results.

\section{RESULTS}

\subsection{X-ray Imaging}

It should be noted that this experimental work was performed by a collaborator in Department of Medical
Physics and Biomedical Engineering, UCL. The system and parameters for the X-ray imaging used is as follows in experiment [10]. The X-ray source is composed by using the ordinary test set-up for an Edge-Illumination imaging system where a sample mask that shapes the beam before it interacts with the sample, and an analyser which is composed of a second mask and a digital detector. This method generally is capable of inspecting materials with hidden flaws by using short-wavelength electromagnetic radiation to penetrate into various materials. The variations in the transmitted X-ray intensity are used to determine the thickness or composition of the object or flaws in the object.

Fig. 1 shows a conventional X-ray image of an impacted cross-ply composite plate, provided by collaborators from the Composite Systems Innovation Centre, University of Sheffield. It should be noted that the X-ray testing was performed on a different, but similar plate to the specimens. The oval shape and the marking out of the damage extremities can be clearly seen. The high black density region is significant compared to other regions, which identifies the location of the impactor head. This could correspond to a small degree of fiber fracture under the impactor head. The high contrast region marked the boundaries between the undamaged and damaged regions, which could be contributed to delamination and matrix cracks. The low contrast regions correspond to the undamaged regions, where no significant changes could be detected. Based on the report by the collaborator, the extended length beyond the impactor-located damage area (15 $\mathrm{mm}$ in diameter) were estimated to be approximately $20 \mathrm{~mm}$ and 25 $\mathrm{mm}$ respectively on the left and right sides, making the total length of the defective region approximately $60 \mathrm{~mm}$ (in $x$-direction). Due to the oval shape, the widths (minor diameters) varied from $5 \mathrm{~mm}$ to $30 \mathrm{~mm}$ across the defective region. Unfortunately there was no scale provided on the image.

Fig. 2 presents the reconstructed X-ray images on one of the two tested composite plates that are based on the edge-illumination technique, performed in the Department of Medical Physics and Biomedical Engineering, University College London. The method enables dark-field imaging by using incoherent illumination and operates with broadband radiation [11]. The same composite panels were used in their studies and it is expected that these results could provide some extra information about the impact damage. As a preliminary demonstration, the extracted images show a strong differential contrast for the composite plate. The presence of the high contrast of 
adjacent densities can be clearly observed from both vertical and horizontal X-ray scattering, which reveal defects inside the plate. The bright lines could indicate local fiber debonding and the two small bright areas which nearly resemble the shape seen in Fig. 2 could probably mark the area of matrix cracks in the plate. This bright area could be used to approximate the size of impact damage in the plate. However, no further information is obtained from the collaborator since this project is still under development. Overall, the damaged region, shape and the extent of the impact damages were observed from the X-ray analysis.

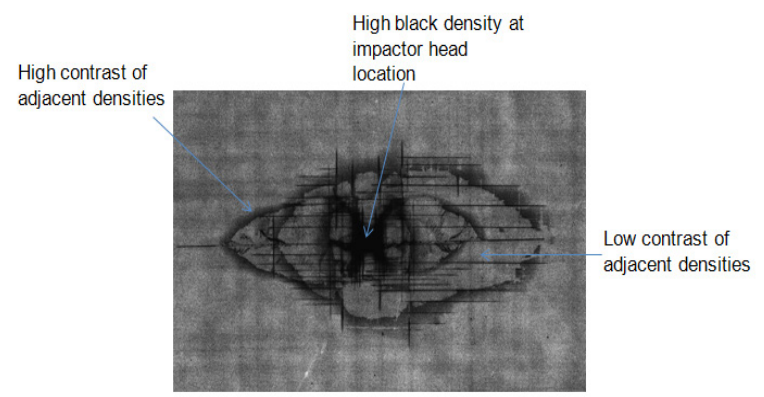

Fig. 1. X-ray images of composite plate impacted at $7.4 \mathrm{~J}$ with impact damage; provided by collaborator in Composite Systems Innovation Centre, University of Sheffield
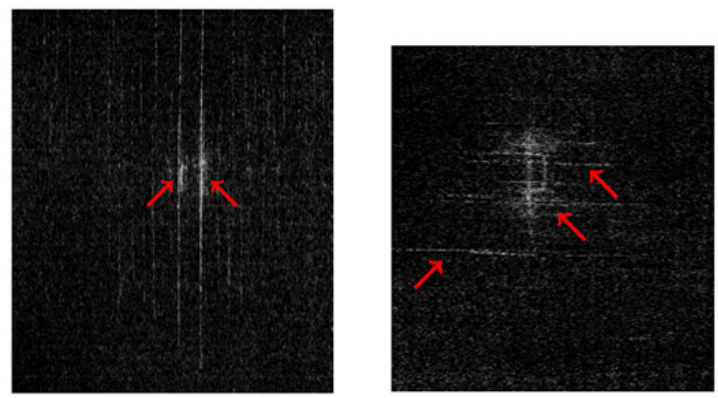

Fig. 2. X-ray images of composite plate impacted at $7.4 \mathrm{~J}$ with impact damage; a) vertical scattering; and b) horizontal scattering

\subsection{Ultrasonic C-scan}

An immersion ultrasonic C-scan method was performed to obtain an approximation of the size, shape and depth of the impact damage in the defective composite plates. The method involved the detection of echoes produced when an ultrasonic pulse was reflected from a discontinuity or an interface in the plates.

The C-scan inspection was performed on one small cross-ply plate due to the requirement of cutting the plate into a small piece for immersion in the water tank. The plate was cut to $200 \mathrm{~mm}$ length and
$110 \mathrm{~mm}$ width, with thickness of $2 \mathrm{~mm}$. The impact was located approximately at the middle of the cutout plate. A $5 \mathrm{MHz}$ focused ultrasonic transducer was used with a focal length of $76.2 \mathrm{~mm}$. A focused immersion transducer was used because it expansion the sensitivity to small defects or other reflectors. For longitudinal wave travelling in thickness direction of the small cross-ply plate at $2700 \mathrm{~m} / \mathrm{s}$ speed, the wavelength was estimated to be $0.54 \mathrm{~mm}$. The transducer was mounted perpendicular to the surface of the small cross-ply plate. The distance of water path was set to be about 76.2 mmbetween the transducer and test plate. The reason was to match the focal length of the transducer, where the signal with the highest amplitude was located. The scanned area was $40 \mathrm{~mm} \times 40 \mathrm{~mm}$. The inspection resolution was $1 \mathrm{~mm}$ in both the $x$ - and $y$-direction for the amplitude $\mathrm{C}$-scan images as shown in [12].

The C-scan display records echoes from the internal portions of the test plate as a function of the position of each reflecting interface. The corresponding wavelength in the composite panel is $0.54 \mathrm{~mm}$. For the C-scan image representation, two different time gating settings were used. The first time gate was set to capture the positive maximum of reflections from the surface. The second time gate was set to capture the negative minimum amplitude that corresponds to the reflections within the plate.

Fig. 3 presents typical received time traces measured from the front surface. The time traces were obtained at four locations, all located at $y=20$ $\mathrm{mm}$, but $x$ positions were varied: $5 \mathrm{~mm}, 15 \mathrm{~mm}, 25$ $\mathrm{mm}$ and $35 \mathrm{~mm}$. The signal monitored at position $(x$ $=5 \mathrm{~mm}, y=20 \mathrm{~mm}$ ) represents a signal collected at the undamaged area. The green dashed line $(x=25$ $\mathrm{mm}, y=20 \mathrm{~mm}$ ) corresponds to the reflection from the dented and cracked area (caused by the impact). Measuring the time of flight from the front surface reflection and knowing the thickness and wave speed of the material (approximately $2700 \mathrm{~m} / \mathrm{s} \pm 10 \%$ ), one can determine the arrival time of the reflection from the back-wall surface. Since the front surface reflection (first echo) arrived at $98 \mu$ s, the back-wall reflection was calculated to arrive at approximately $99.5 \mu \mathrm{s} \pm 10 \%$. The time interval of echoes from every layer cannot be detected as the wavelength $(0.54 \mathrm{~mm})$ is larger than the nominal thickness of each layer $(0.25$ $\mathrm{mm}$ thick). Fig. 3 shows three groups of reflections that can be observed based on their arrival times. These groups correspond to the reflections from (i) the surface, (ii) within the plate thickness and (iii) backwall of the plate. 


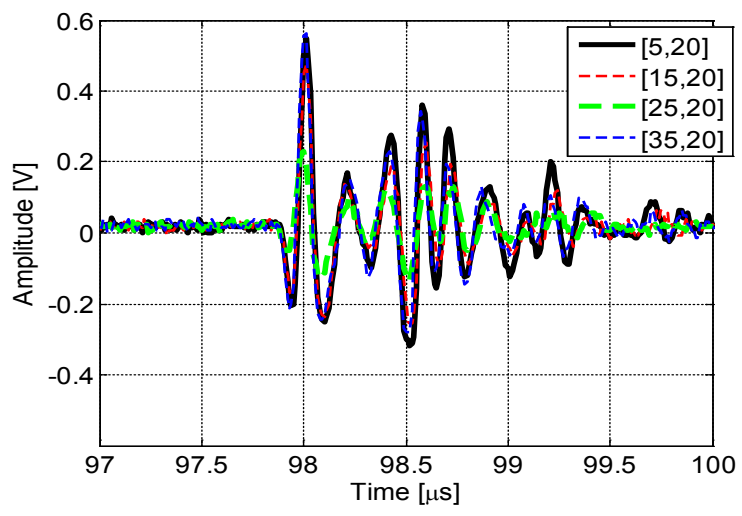

Fig. 3. Comparison of response signals at various locations; signal at location $x=5 \mathrm{~mm}, y=20 \mathrm{~mm}$ corresponds to the undamaged signal; pulse-echo mode; focused; $5 \mathrm{MHz}$ frequency

From Fig. 3, it can be observed that the lowest reflected amplitude $(0.2 \mathrm{~V})$ was obtained from the signal measured at the center of the impacted area $(x$ $=25 \mathrm{~mm}, y=20 \mathrm{~mm}$ ). The other three signals have higher amplitudes $(0.6 \mathrm{~V})$ of the surface reflection, which described the undamaged and smoother surface. For the second group of the reflections within the plate, multiple peaks of reflections occurred, which can be due to local higher scattering from within the plate. Again it can be observed that the lowest reflection amplitude $(0.1 \mathrm{~V})$ was obtained at the impacted area. This shows that the irregular surface (at the impactor location) greatly degraded the normal incident and reflected waves. Meanwhile, the other three signals have inconsistencies in their amplitudes. This may be related to the variations and changes in the interlaminar condition caused by the impact on the surface. What is interesting in this data is that the assumed undamaged signal (based on visual inspection on the surface area) also produced multiple reflections as the other signals. The highest reflected amplitude was observed at $98.5 \mu \mathrm{s}$. Briefly, the arrival time matches approximately to a quarter of the plate thickness. This could indicate the through-thickness location of the delamination as the delamination is normally located in-plane between plies, which produces high reflections. Turning now to the last reflected group (the back-wall reflections), it can be observed that the highest amplitude reflection was obtained from signal monitored at the undamaged area $(x=5 \mathrm{~mm}, y=20 \mathrm{~mm})$. This could be due to less wave attenuation and scattering between the plies. Meanwhile, the back-wall reflections from the damaged area are lower than that observed in the undamaged location, which relates to the scattering by the impact damage within the plate.

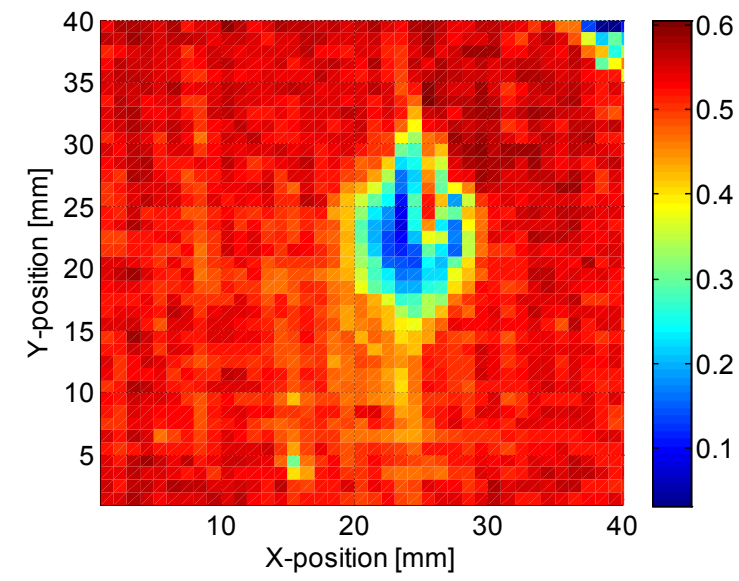

Fig. 4. C-scan image of the front surface of the $2 \mathrm{~mm}$ cross-ply specimen; $40 \mathrm{~mm} \times 40 \mathrm{~mm}$ scanned area; $5 \mathrm{MHz}$ frequency; $76.2 \mathrm{~mm}$ transducer focal length

Fig. 4 shows the C-scan image of the front surface of the test plate (that has a smoother surface compared to the back-wall surface). This image was generated using the maximum peak amplitude of the first reflection. Referring to Fig. 3, the first reflection is mainly a reflection from the plate surface and therefore it is expected not to be sensitive to the internal defects. From Fig. 4, the impact damage is located in the middle of the scanned area. The oval shape region reasonably matches the $15 \mathrm{~mm}$ diameter of the hemisphere shaped impactor head. The oval shaped section with lower amplitude region, ranging from $0.1 \mathrm{~V}$ to $0.4 \mathrm{~V}$, can be clearly observed with an approximate length of $10 \mathrm{~mm}$ ( $x$-axis) and width of $15 \mathrm{~mm}$ ( $y$-axis). This lower amplitude at the impacted area can be explained by the fact that the incident wave encounters the dented surface, which causes the wave to be reflected back at different angles and causes energy loss due to the scattering at the surface. Meanwhile, the rest of the area has a consistently higher and uniform reflected amplitude within a range of $0.5 \mathrm{~V}$ to $0.6 \mathrm{~V}$ due to the smooth plate surface.

Fig. 5 shows a C-scan image of the same section as Fig. 4, but plotted using the minimum negative amplitude, time gated after the surface reflection. This image represents the internal reflections from within the plate. From the figure, the oval shape with relatively low minimum amplitude $(0 \mathrm{~V}$ to $0.2 \mathrm{~V})$ as similarly obtained from Fig. 4 can be seen. This shows that the surface indentation not only reduced the normal incident wave but also the reflected wave from within the plate. It also appears there is another large region (half oval shape) with the highest negative amplitude $(0.2 \mathrm{~V}$ to $0.3 \mathrm{~V})$. This is not observed in Fig. 
6 , which is time gated for the first surface reflection only.

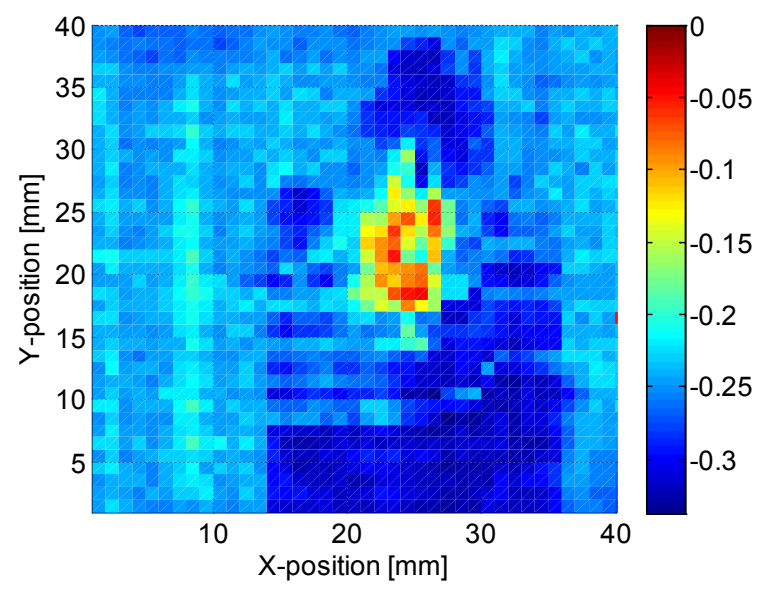

Fig. 5. C-scan image of negative peak amplitude measured from the frontal surface of the $2 \mathrm{~mm}$ cross-ply panel; $40 \mathrm{~mm} \times 40 \mathrm{~mm}$ scanned area; $5 \mathrm{MHz}$ frequency; $76.2 \mathrm{~mm}$ transducer focal length

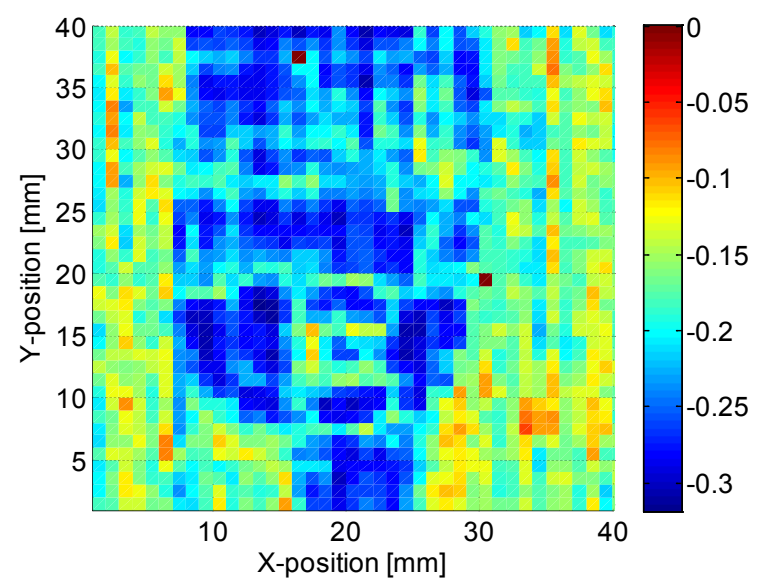

Fig. 6. C-scan image of negative peak amplitude measured from the back-wall surface of the $2 \mathrm{~mm}$ cross-ply panel; $40 \mathrm{~mm} \times 40 \mathrm{~mm}$ scanned area; $5 \mathrm{MHz}$ frequency; $76.2 \mathrm{~mm}$ transducer focal length

The same time gating (after surface reflection; negative minimum amplitudes) was also used from the back wall surface (rougher surface compared to the front surface). Fig. 6 shows an approximately similar pattern as obtained in Fig. 5, although the sharp oval shape area $(0 \mathrm{~V}$ to $0.2 \mathrm{~V})$ was not observed in this figure as the back surface was not dented. The extent of the impact damage $(0.2 \mathrm{~V}$ to $0.3 \mathrm{~V})$ is reproducible although the surface of the back-wall is rougher. This time gated approach seems to be more sensitive to the extent of the impact damage in the composite laminate. The possible defective area is much larger, about $20 \mathrm{~mm}$ and $40 \mathrm{~mm}$ in the $x$ - and $y$-axis respectively, and the damage level (indicated by different amplitude relative to the neighborhood area) is significant. However, the width of the damaged area could be larger than the scanned area, and may spread in a similar oval-shaped pattern. In relation to that point, Sohn et al. [13] have found that the impact response and damage states in flat composite panels is dependent on the diameter of the spherical impactor head. Although this result does not give full information about damage distribution through the thickness, it has provided a useful approximation of size and depth of the impact damage in the composite plate. It is worthwhile at this stage to use this information for the comparison between the numerical predictions and the experimental results of the guided wave scattering at impact damage.

\subsection{Guided Ultrasonic Waves}

A piezoelectric transducer consisting of a piezoelectric disc and a brass backing mass was bonded to the plate using Loctite 2-part epoxy glue approximately $50 \mathrm{~mm}$ from the center of the impact damage. The first antisymmetrical $\left(A_{0}\right)$ guided wave mode with an excitation frequency of $100 \mathrm{kHz}$ was chosen below the cutoff frequencies for the higher wave modes. The excitation signal consisted of a 5-cycle Hanning windowed toneburst generated by a programmable function generator. The wave propagation and scattering around defects is measured using a commercially available heterodyne laser vibrometer fixed to a scanning rig, which permits the noncontact and remote sensing of the guided waves. The voltage signal corresponds to the velocity of the outof-plane-displacement of the specimen surface. The measurement was performed on the area of $40 \mathrm{~mm} \times$ $40 \mathrm{~mm}$ area containing the impact damage with a step size of $1 \mathrm{~mm}$ in both directions. The time traces of the received signals were collected and further processed in Matlab. From the scanned time signals, wave field images were reconstructed and processed to study the interaction of the guided wave with the impact damage.

Fig. 7 presents the guided wave fields at various time snapshots, respectively for damaged composite plate 1 and 2. It can be seen that the incident wave interacts with the impact damage and causes scattering within the damaged region. Relatively weak scattering by the damage is present when the incident wave arrives (Figs. 7a and c), then a significant increase of the scattering is apparent when wave has travelled past the damaged area (Fig. $7 \mathrm{~b}$ and d). Based on the FE study, a significant portion of the waves is also 
reflected back from the exit of the impact damage. These reflected waves travel within the damaged region and keep reflecting back at both entrance and exit of the impact damage. As a consequence of these multiple reflections, a considerable amount of guided wave energy is trapped inside the impact damage area. This causes an increase in the amplitude of the wave in that region.

The amplitude of the transmitted waves diminished noticeably after passing through the impacted area. Similar wave behavior was also observed by Sohn et al. [13], where the measurement was performed on a quasi-isotropic composite plate. This finding however is contradictory to some of the FE simulation results [12], where a large amount of transmitted wave can be observed. However, some FE results have demonstrated the reduction in the amplitude past the delamination area. The FE simulations for the delamination placed at 0.5 $\mathrm{mm}$ depth is in agreement with this experimental measurement. Comparing both specimens, which were impacted with same $7.4 \mathrm{~J}$ impact energy, it can be seen that guided wave scattering in both plates are unique and such variations are expected due to the complexity in the failure mechanism of impact damage.

Fig. 8 presents the image of the maximum amplitude of the signal envelope over the damaged areas in both composite specimens. Areas of higher amplitudes can be seen, that occur close to the impact location center ( $x=20 \mathrm{~mm}, y=20 \mathrm{~mm}$ ). This indicates the presence of severe damage such as a delamination or fiber and matrix cracking, and matched reasonably well with the visually observed size of the impact damage on the plates as well as the $\mathrm{X}$-ray and $\mathrm{C}$-scan images. Meanwhile, the undamaged area is represented by the low amplitude distribution. From the figure, three different zones can be observed and each zone has its own wave propagation behavior; (i) Zone 1: before the impact damage $(x<15 \mathrm{~mm})$, (ii) Zone 2: across the impact damage $(15 \mathrm{~mm}<x<25$ $\mathrm{mm}$ ), and (iii) Zone 3: behind the impact damage ( $x$ $>25 \mathrm{~mm})$.

The first zone (before damage) shows the incident waves propagating towards the impact damage location. It is also can be seen there were reflected waves propagating back towards the excitation source. Some periodical increase and decrease of the amplitude is visible in the region around $x=15 \mathrm{~mm}$, potentially indicating the interference between the incident and the reflected waves at the impact damage. In zone 2, high amplitudes of the A0 mode signals are visible, which could indicate the multiple reflections and scattering events within the impact damage area. Meanwhile, in zone 3, the transmitted waves propagating out from the damaged area are seen to be blocked in certain direction with significantly reduced signal amplitudes. Considerable waves transmitted
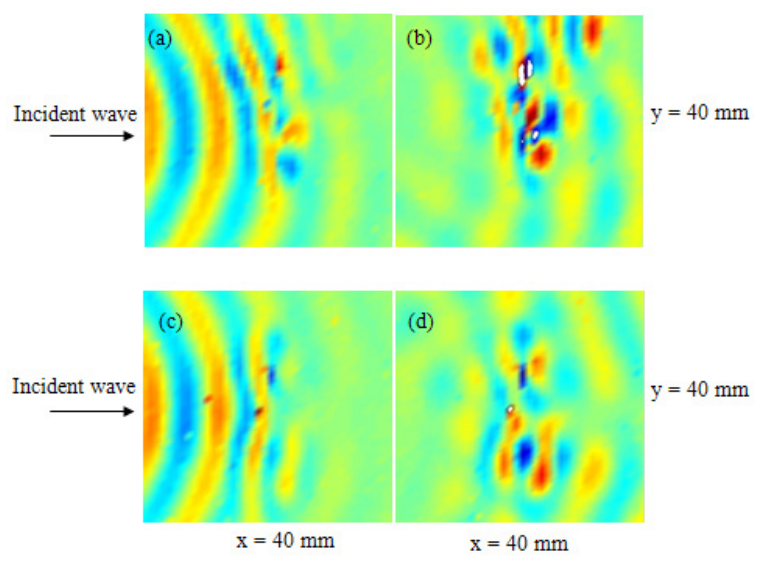

Fig. 7. Guided wave displacement fields in two composite plates; Plate No. 1, snapshot time; a) $20 \mu$ s and

b) $30 \mu \mathrm{s}$; Plate No. 2, snapshot time; c) $20 \mu \mathrm{s}$

and d) $30 \mu \mathrm{s} ; 7.4 \mathrm{~J}$ impact; $40 \mathrm{~mm} \times 40 \mathrm{~mm}$ scanned area
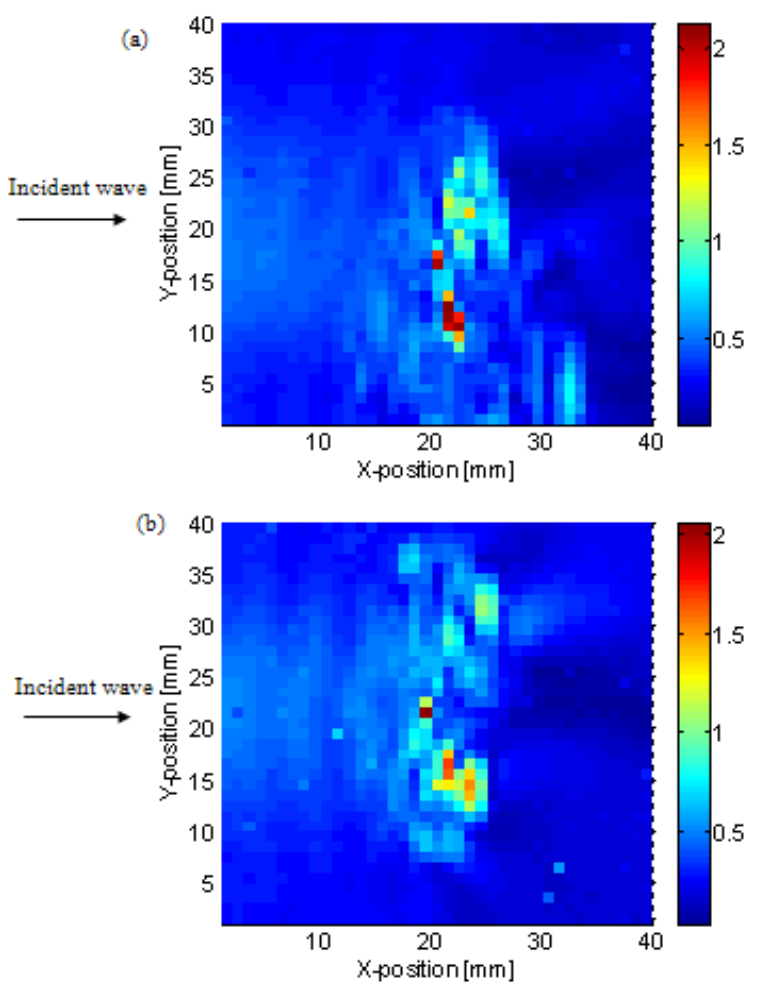

Fig. 8. Maximum amplitudes of guided wave pulse across damaged area of composite plate: a) Plate 1; b) Plate 2; frequency $100 \mathrm{kHz} ; 40 \mathrm{~mm} \times 40 \mathrm{~mm}$ area with impact location at center $(x=20 \mathrm{~mm}, y=20 \mathrm{~mm})$ 
across the impact damage indicate that probably little mode conversion occurred as has been observed from the FE simulations. The cross-section of the impact damage in Plate no. 1 can be roughly approximated with length of $10 \mathrm{~mm}$ ( $x$-axis) and width of $20 \mathrm{~mm}$ ( $y$-axis), identified by the higher amplitude maxima. For Plate no. 2, the cross section area of the impact damage can be estimated to be about $10 \mathrm{~mm} \times 25 \mathrm{~mm}$.

Referring to the FE simulation results in [12] and [14] good agreement between the experimental and simulated result was achieved. Similar wave propagation behaviour before and within the impact damage can be observed from both results. The increase in amplitudes identifies the localization of the impact damage in the measured area. There was a significant difference in the wave behaviour behind the damage location, where many FE simulations did not predict a persistent amplitude drop compared to the experimental results. Details of the impact damage such as depth, exact length and width as well as its complex scattering are further investigated here [15] and [16]. From this study, it is evident that the impact damage can be detected using the guided ultrasonic wave measurement.

\section{CONCLUSIONS}

This paper reports the characterization of impact damage using 3 different NDE methods: X-ray, ultrasonic C-scan and guided ultrasonic waves. From the X-ray measurement, it has shown that it can indicate the local fiber debonding and mark the area of matrix cracks, whereas the ultrasonic immersion $\mathrm{C}$-scan provides a useful approximation of size and depth of the impact damage. From the scattering of the guided wave at the impact damage, this method efficiently localized the impact location and provide details such as depth, exact length and width of the impact damage. Comparing these three methods, the guided ultrasonic waves method perfectly demonstrated the capability to detect impact damage in composite plates using smaller equipments that are less expensive and have a quick experimental setup and measurements.

\section{ACKNOWLEDGEMENTS}

The author gratefully acknowledges the support in funding by Universiti Teknologi Mara (UiTM), Malaysia, especially from the Geran Dana Pembudayaan Penyelidikan (600-RMI/RAGS 5/3 (12/2015).

\section{REFERENCES}

[1] Murat, B.I.S., Rahman, A.A.A. (2017). Study of impact damage behavior in woven carbon fiber plates. Procedia Engineering, vol. 170, p. 47-54, D0l:10.1016/j.proeng.2017.03.009.

[2] Richardson, M.O.W., Wisheart, M.J. (1996). Review of lowvelocity impact properties of composite materials. Composites Part A: Applied Science and Manufacturing, p. 1123-1131, DOI: 10.1016/1359-835X(96)00074-7.

[3] Mal, A.K., Shih, F., Barnerjee, S. (2003). Acoustic emission waveforms in composite laminates under low velocity impact. Proceedings SPIE, vol. 5047, p. 1-12, D0I:10.1117/12.484448.

[4] Swait, T.J., Jones, F.R., Hayes, S.A. (2012). A practical structural health monitoring system for carbon fibre reinforced composite based on electrical resistance. Composites Science and Technology, vol. 72, no. 13, p. 1515-1523, D0l:10.1016/j. compscitech.2012.05.022.

[5] Takeda, N., Okabe, Y., Kuwahara, J., Kojima, S., Ogisu, T. (2005). Development of smart composite structures with small-diameter fiber Bragg grating sensors for damage detection: Quantitative evaluation of delamination length in CFRP laminates using Lamb wave sensing. Composites Science and Technology, vol. 65, no. 15-16, p. 2575-2587, D0I:10.1016/j.compscitech.2005.07.014.

[6] Raghavan, A., Cesnik, C.E.S. (2007). Review of guided-wave structural health monitoring. The Shock and Vibration Digest, vol. 39, no. 2, p. 91-114, D0l:10.1177/0583102406075428.

[7] Freemantle, R.J., Hankinson, N. Brotherhood, C.J. (2005). Rapid phased array ultrasonic imaging of large area composite aerospace structures. Insight - Non-Destructive Testing and Condition Monitoring, vol. 47, no. 3, p. 129-132, D0l:10.1784/ insi.47.3.129.61315.

[8] Hay, T.R., Royer, R.L., Gao, H., Zhao, X., Rose, J.L. (2006). A comparison of embedded sensor Lamb wave ultrasonic tomography approaches for material loss detection. Smart Materials and Structures, vol. 15, no. 4, p. 946-951, DOI:10.1088/0964-1726/15/4/007.

[9] Murat, B.I.S., Fromme, P. (2013). Detection of impact damage in composite panels using guided ultrasonic waves. Proceedings of SPIE - Health Monitoring of Structural and Biological Systems, vol 8695, Dol:10.1117/12.2009459.

[10] Endrizzi, M., Murat, B.I.S., Fromme, P., Olivo, A. (2015). Edgeillumination X-ray dark-field imaging for visualising defects in composite structures. Composite Structures, vol. 134, p. 895899, D0I:10.1016/j.compstruct.2015.08.072.

[11] Endrizzi, M., Diemoz, P.C., Millard, T.P., Jones, J.L., Speller, R.D., Robinson, I.K., Olivo, A. (2014). Hard X-ray dark-field imaging with incoherent sample illumination. Applied Physics Letters, vol. 104, no. 2, 024106, D0l:10.1063/1.4861855.

[12] Murat, B.I.S., Fromme, P. (2016). Propagation and scattering of guided waves in composite plates with defects. International Journal of Automotive and Mechanical Engineering, vol. 13, no. 3, p. 3728-3741, DOI:10.15282/ijame.13.3.2016.15.0305.

[13] Sohn, H., Dutta, D., Yang, J.Y., Park,H.J., DeSimio, M., Olson, S., Swenson, E. (2011). Delamination detection in composites through guided wave field image processing. Composites Science and Technology, vol. 71, no. 9, p. 1250-1256, DOI:10.1016/j.compscitech.2011.04.011. 
[14] Michaels, T.E., Michaels, J.E., Ruzzene, M. (2005). Damage detection in plate structures using sparse ultrasonic transducer arrays and acoustic wavefield imaging. AIP Conference Proceedings, vol. 760, no. 1, 938-945, DOl:10.1063/1.1916774.

[15] Murat, B.I.S., Khalili, P., Fromme, P. (2014). Impact damage detection in composite panels using guided ultrasonic waves.
AIP Conference Proceedings, vol 1581, no. 1, p. 286-293, Dol:10.1063/1.4864832.

[16] Murat, B.I.S., Fromme, P. (2016). Finite element modeling of guided wave scattering at delaminations in composite panels. Proceedings of SPIE - Health Monitoring of Structural and Biological Systems,vol. 9805, D0I:10.1117/12.2220409. 